\title{
THE EFFECT OF TOXAEMIA OF PREGNANCY UPON THE FOETUS AND NEWBORN CHILD*
}

\author{
BY \\ AGNES A. BRASH, M.D., D.C.H. \\ (From the Department of Child Life and Health, University of Edinburgh)
}

There exists a widespread impression that the infants of mothers suffering from toxaemia of pregnancy have a less than normal prospect of surviving the newborn period, and that if they survive their progress is less satisfactory than that of infants born of healthy women. There is also a tendency to attribute, somewhat vaguely, post-natal symptoms in these infants to the maternal toxaemia. The rather scanty literature is not very informative with regard to the prospects of survival of liveborn infants of toxaemic mothers, though numerous authors have emphasized the increased likelihood of foetal death or premature birth. Tunis (1928) considered that direct transmission of eclampsia was unimportant as a cause of foetal death, and concluded that prematurity was the major factor, associated with a greater risk of intra-uterine asphyxia. Strauch (1939) also commented on the high foetal mortality, which he ascribed in part to prematurity, in part to placental damage, and in part to the asphyxia produced by the maternal convulsions. He argued in favour of the occurrence of neonatal eclampsia, quoting previous authors in support of this. Peckham (1933) analysed the foetal mortality and found it to be directly proportional to the severity and duration of the toxaemia, and inversely proportional to the duration of pregnancy at the time of onset of the toxaemia. He included nephritic cases and found that the mortality was much higher amongst the infants of nephritics than in those of nonnephritics.

Tyson and Bowman (1931) studied twenty-nine cases of eclampsia and forty-nine of pre-eclamptic toxaemia, and found the foetal mortality in each group to be higher than the average, and in the former higher than in the latter. They ascribed the high mortality solely to premature birth resulting from the toxaemia. In a follow-up of the survivors, over periods'varying from one month to one year, they found no evidence of any remote ill-effects of the maternal toxaemia.

- Part of a thesis accepted for the devree of M.D. University of Edinburgh.
Tunis (1928) and Von Reuss (1916), whom he quotes, also carried out a follow-up of their cases, and found no evidence of any ill effects. Pilcz (1900), on the other hand, quoted by Tunis, gave a mortality rate of 59 per cent. among 350 children of eclamptic mothers, but Tunis points out that he drew his material from an institution which had in any case a high death rate.

Ludlow (1933) assessed the incidence of stillbirth and neonatal death, and the progress of the survivors, among 148 infants of toxaemic mothers, and made a comparison with infants of healthy mothers. He concluded that full-term infants of toxaemic mothers have a higher incidence of stillbirth and neonatal death, a lower average birthweight, and a less satisfactory gain in weight while in hospital, than those of healthy mothers; that eclampsia has no worse influence than pre-eclamptic toxaemia, but that nephritis has a worse effect than either. Premature infants, however, showed a wholly different comparison; those born of toxaemic mothers had a lower neonatal death rate and a better average weight-gain than those of healthy mothers, and the infants of nephritic mothers fared better still. Necropsies were performed on a number of the infants dying in the neonatal period; four are said to have shown evidence of toxaemia, this evidence being defined as autolysis, placental infarction, asphyxia, and maceration.

Drillien (1947a, b, c) made a study of prematurity, stillbirth, and neonatal death, and concluded that although toxaemia has a significant and marked effect in causing premature birth it has no adverse effect on the foetus and premature infant (as judged by survival rates) other than that on the birthweight. She found that the survival rates among premature infants were slightly higher for the infants of toxaemic than for those of healthy women. She suggests that toxaemia might be an important factor in the production of intra-uterine death, with or without demonstrable asphyxia.

Peckham (1933) states that breast feeding is less successful in toxaemic than in healthy mothers, but he gives no evidence in support of this view. 
Ludlow (1933) found that the milk of toxaemic mothers had no apparent ill effects upon their infants.

Rucker and Connell (1924), in the course of investigating the normal blood pressure in the newborn, concluded on the basis of five cases that - toxic conditions of the mother seem to have some influence on the blood pressure of the child, which is more marked the first day of life.' Browne and Dodds (1936) made daily readings of the systolic blood pressure of three infants whose mothers had hypertension before delivery, and found them not significantly higher than those of six normal controls.

Smith (1945) quotes Salmi as stating that albuminuria occurs more often in the infants of albuminuric mothers than in those of healthy mothers.

\section{Present Investigation}

In view of the somewhat conflicting evidence, the present investigation was undertaken primarily to determine whether toxaemia of pregnancy could be shown to have any effects on liveborn infants, and particularly on those surviving the neonatal period. It was accepted that maternal toxaemia was a cause of prematurity, and a comparison was made between the progress of premature infants of toxaemic and non-toxaemic mothers, and similarly between fullterm infants of toxaemic and non-toxaemic mothers. Information was also added with regard to stillbirths and neonatal deaths.

Clinical material. All the infants studied were born in the Simpson Memorial Maternity Pavilion, Royal Infirmary, Edinburgh, during the years 1942-47, with the exception of a small number of premature babies admitted within a few hours of birth from the hospital district during 1946. In the case of stillbirths and neonatal deaths, information was obtained from mothers' and infants' case notes and post-mortem reports and not from personal observation. The cases were as far as possible consecutive, but in some instances cases had to be excluded on account of incomplete or missing maternal case records; as far as could be determined, this did not materially affect the sample.

The infants included in the premature series were all born during 1946, though not all were seen personally. In the series of mature surviving infants, all were observed personally during 1947. Those in the toxaemic group were consecutive livebirths over a period of approximately six months; the controls were obtained by random sampling of full-term infants in the same nurseries at the same time.

Definition of toxaemia. The term 'toxaemia of pregnancy' has been used throughout to include eclampsia, pre-eclampsia, and hypertension, whether arising for the first time during pregnancy or existing previously. Any case diagnosed as nephritis has been excluded; the diagnosis of nephritis rested on a history or on signs of renal damage before the twenty-fourth week of pregnancy. Three cases were thus excluded in each of the stillbirth and neonatal death series, and one in the series of mature surviving infants: cases of all grades of severity have been included, and an arbitrary definition of severity has been adopted which classified as 'severe' all cases reaching a diastolic blood pressure of $130 \mathrm{~mm}$. or more, and cases with a diastolic pressure of $110 \mathrm{~mm}$. if they had also a well marked albuminuria.

\section{Surviving Full-Term Infants}

One hundred and twenty full-term liveborn infants of toxaemic mothers were compared with the same number of controls born to non-toxaemic mothers. Comparison was made of the birthweight, initial loss of weight, progress as judged by weightgain, lethargy, liability to infection and other morbid conditions, oedema, albuminuria, and blood pressure. The maternal histories and lactation in the two groups were also compared.

Maternal history. In the toxaemic group, the toxaemia (including eclampsia) was classified as severe in twenty-one instances and mild or moderate in ninety-nine. The duration of toxaemia was as follows:

$$
\begin{array}{lr}
1 \text { week or less } & \text { o } \\
1 \text { to } 4 \text { weeks } & 24 \\
4 \text { to } 8 \text { weeks } & 54 \\
\text { More than } 8 \text { weeks } 22 \\
\text { Uncertain } & 20
\end{array}
$$

A comparison of other features of the maternal histories is shown in table 1 .

\section{TABUE 1} COMPARISON OF MATERNAL HISTORIES

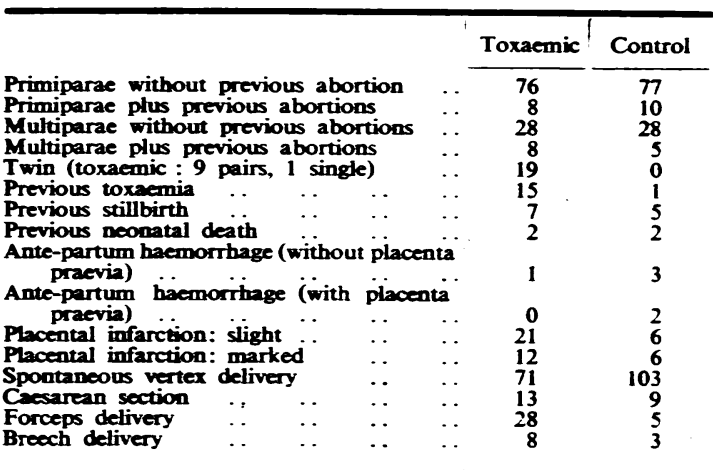

Birthweight. The distribution of birthweights of all the infants in the two groups is shown in fig. 1 , $5 \frac{1}{2} \mathrm{lb}$. $(2,500 \mathrm{~g}$.) being taken as the accepted standard of maturity. The mean birthweight in the toxaemic group was $7 \mathrm{lb} .3 \mathrm{oz}$., and that in the control group $7 \mathrm{lb.} 6 \frac{1}{2} \mathrm{oz}$.

Initial weight loss. Fig. 2 shows the relation between birthweight and initial weight loss. The initial loss tends, as might be expected, to vary with birthweight, but more noticeably so above a birthweight of $7 \mathrm{lb} .8 \mathrm{oz}$. The curves for toxaemics and controls are in general similar. In the toxaemic 
group, the mean initial loss was $9.8 \mathrm{oz}$ with a range of 4 to $12 \mathrm{oz}$; in the control group it was $9.3 \mathrm{oz}$. with a range of 4 to $17 \mathrm{oz}$.

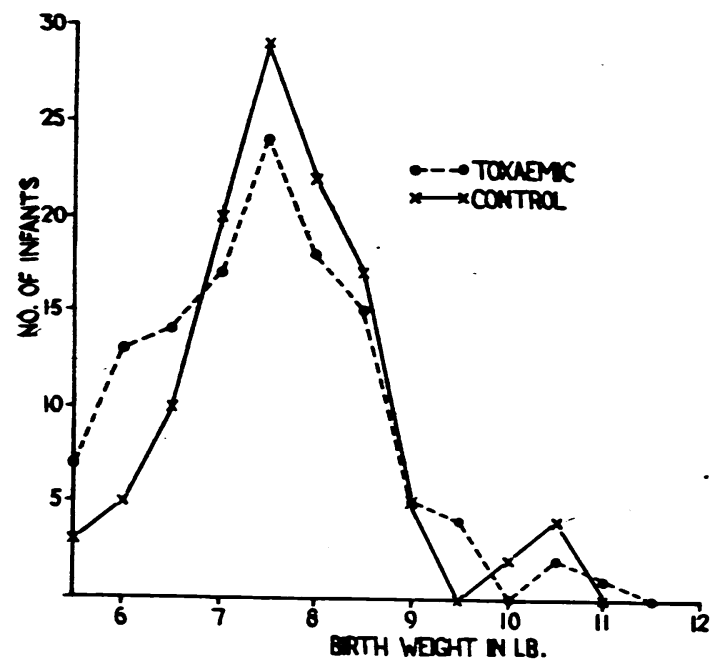

FIG. 1.-Distribution of birthweights of full-term infants of toxaemic mothers and controls.

Weight gain. The infants in the toxaemic and control groups were each divided into fifteen subgroups on the basis of birthweight (using a weight range of $4 \mathrm{oz}$. in the case of the smaller infants and 8 or $12 \mathrm{oz}$. in the case of the heavier infants). The mean weight curves of the toxaemic and control infants in each sub-group were then compared up to the eighth day of life. Detailed figures are given elsewhere (Brash, 1948). It was found that in three instances the gain in weight of the toxaemic infants was inferior to the controls, in three it was superior, and in the remaining nine instances there was no significant difference. It is concluded that this comparison does not furnish any evidence of the full-term infants of toxaemic mothers being at a disadvantage as regards gain in weight during the first eight days of life when compared with nontoxaemic controls of similar birthweight.

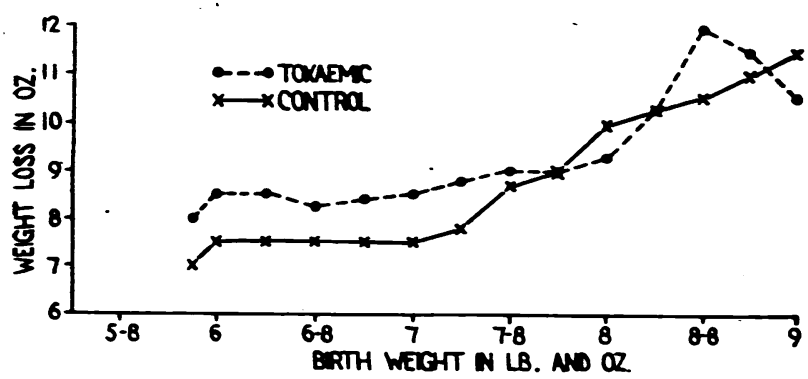

Fig. 2.-Relation between birthweight and initial weight loss.
Lethargy and stock. Abnormal lethargy for some days after birth is shown principally by slowness in feeding, whether at the breast or from a bottle. Of the infants of toxaemic mothers, eleven were classified as lethargic, of the controls only one. Of the eleven, the mothers of three had had their labour induced and had been heavily sedated before an abnormal delivery, six more had an induction of labour, one having also a difficult natural delivery, one had a Caesarean section, and one had a moderate amount of sedative before delivery. The mother of the one control infant had also been given a moderate amount of sedative before delivery.

Evidence of shock at delivery was observed in twenty-one of the toxaemic group (three also showing lethargy for several days after birth), and in sixteen in the control group.

Incidence of infection. Nine infants in the toxaemic and eight in the control group acquired infections during the neonatal period. In the toxaemic group, three infants had mild attacks of gastro-enteritis, two in the first week, of whom one had nasopharyngitis as well. One developed dacryocystitis in the first week, and two had thrush; one of the latter had pneumonia in the fourth week. One child developed septic spots in the second week, and another a boil in the third week. There was one case of undiagnosed fever and loss of weight in the second week, with quick recovery.

In the control group there were five cases of septic spots and two of thrush, all in the first week; one infant developed a septic hand in the second week.

Other morbid conditions. Five infants in each group displayed some morbid condition, of which details follow.

A. Toxaemic Group. One infant had two convulsions in the first twenty-four hours; this child was delivered spontaneously of a severely toxaemic mother after an induction of labour; there were no other abnormal features, and progress after the first twenty-four hours was uneventful.

One was very lethargic for four days and oedematous for six; there was a single colour change on the second day, and deep physiological jaundice from the third to the eleventh day; there was no gain in weight until the third week, but progress from then on was satisfactory; the mother was suffering from moderate toxaemia, and delivery was spontaneous after an induction of labour.

Two 'murmured' during their first twenty-four hours; each was delivered spontaneously after an induction of labour; the mother of one had severe toxaemia, and of the other moderate hypertension.

B. Control Grour. One infant failed to gain any weight while in hospital, in spite of apparently adequate test-feeds. One lost weight for the first ten days; this infant was artificially fed because the mother had open pulmonary tuberculosis; he presented no abnormal sign other than the loss of weight, and made satisfactory progress after the 
tenth day. Two developed dehydration fever. One had a feeble cry and shallow respirations for the first twenty-four hours, but did well thereafter; this infant had undergone breech delivery.

Oedema. Hallum (1941) states that oedema of the newborn, although common in premature infants, is rare in those born at term. Of 211 cases of oedema occurring in premature infants (from the records of the Birmingham City Maternity Home), thirty-six had a history of maternal toxaemia, but among her own cases six of the mothers were toxaemic.

All the infants in the present series were examined for the presence of oedema. This was found in none of the control group, whereas in the toxaemic group two showed slight oedema of the legs, lasting one and six days respectively; two showed moderate oedema of the legs, lasting six and twelve days respectively. Of the mothers of these infants, one of each pair was suffering from mild and the other from severe toxaemia.

Albuminaria. Young et al. (1941) quote Von Reuss to the effect that albumin was found in 96 per cent. of infants during the first four days of life, and Smith (1945) states that albuminuria is found in themajority of newborn infants, particularly prematures, from the second to the fifth day.

Urine specimens were obtained on the third day from ten infants of the toxaemic group and from twenty-five controls. Albumin was found in only one (10 per cent.) of the former, and in ten (40 per cent.) of the controls.

Blood pressure. Blood pressure readings in small infants are difficult to standardize and record accurately. It is necessary to have the infant at rest ; auscultation of the brachial artery is not practicable by the ordinary methods, and palpation of the radial pulse is often difficult. The width of the cuff used introduces a further variable factor.

Rucker and Connell (1924), using an oscillometer, found the average systolic pressure at birth to be $55 \mathrm{~mm}$. $\mathrm{Hg}$, the average diastolic to be $40 \mathrm{~mm}$, and the pressure to be proportional to the total length of the infant. They do not state the width of the cuff which they used. Woodbury et al. (1938) measured the blood pressure at birth with a cannula in the umbilical artery, and found that the readings corresponded with those obtained by palpation at the wrist.when a $2 \cdot 5 \mathrm{~cm}$. cuff was used; they concluded that the usual $5 \mathrm{~cm}$. cuff gives too low readings. Day (1939) investigated the effect of cuff-width in children and adults; he found that widening the cuff lowers the reading until a certain point is reached, after which the reading remains constant, and concluded that as wide a cuff as possible is the most reliable and should be used. Smith (1945), quoting Woodbury et al., states that a $2.5 \mathrm{~cm}$. cuff must be used, and that the systolic pressure is 70 to $80 \mathrm{~mm}$. $\mathrm{Hg}$ at birth and $95-100 \mathrm{~mm}$. $\mathrm{Hg}$ on the tenth day.

In the present investigation a $6 \mathrm{~cm}$. cuff was used, and the systolic pressure was read by palpation of the radial artery at the wrist. Estimation of the diastolic pressure was not attempted. Difficulty was often encountered in feeling the radial pulse, but in only four cases was it given up as impossible. All readings were made with the infant quiet, but very few during sleep.

In fifty cases in the toxaemic and a hundred cases in the control group a reading was made on the first and on the eighth day of life. In a further twenty cases in each group daily readings were made for the first eight days.

Fig. 3 shows the distribution of all the readings
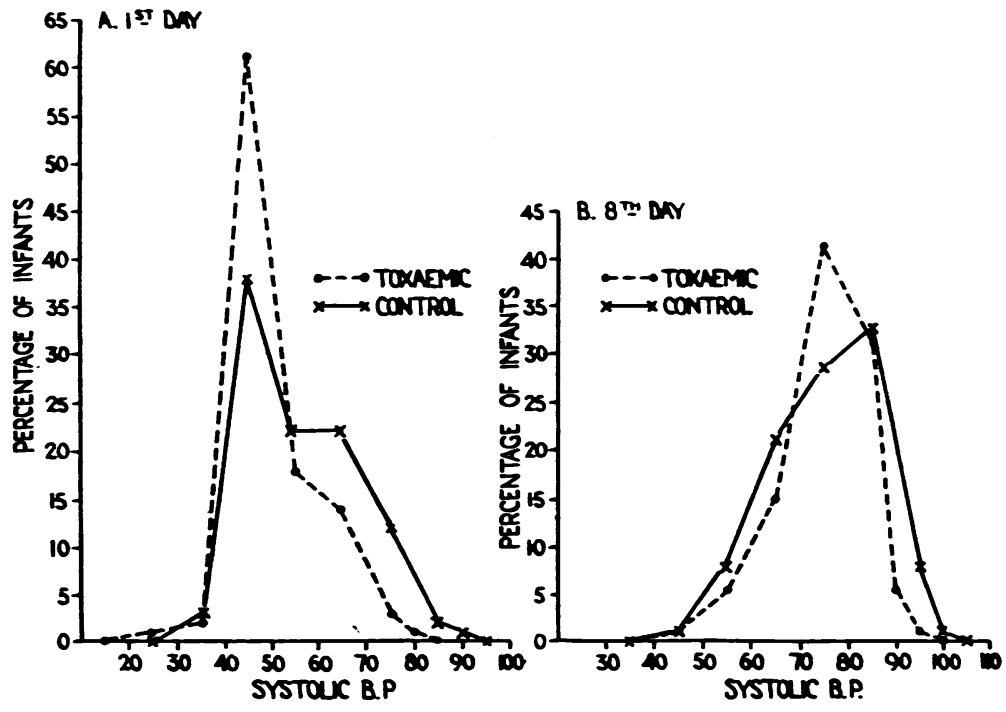

Fig. 3.-Percentage distribution of blood pressures on first and eighth days.

on the first and on the eighth day. It will be seen that the scatter is similar in the two groups, with peaks between 40 and $45 \mathrm{~mm}$. $\mathrm{Hg}$ on the first day, and between 70 and $85 \mathrm{~mm}$. $\mathrm{Hg}$ on the eighth. The average systolic pressure on the first day was 48.3 in the toxaemic group, with a range of 25 to 80 , and 55.4 in the control, with a range of 35 to 90 . On the eighth day it was 74 in the toxaemic group, with a range of 45 to 95 , and 73.9 in the control, with a range of 45 to 100 . Five infants of severely toxaemic mothers gave average readings of $46 \cdot 2$ on the first day, and 73 on the eighth. 
Table 2 gives the individual daily readings made on twenty 'toxaemic' and twenty control infants. Though there was in all cases a rise in pressure by the eighth day, in no instance was it a steady one, and nearly all the infants showed a temporary fall at some point. Several infants in the toxaemic group showed an initial fall in pressure, but so also did several in the control group, and there is no form of curve in the former which is not paralleled in the latter.

TABLE 2

DAILY BLOOD-PRESSURE READINGS IN TOXAEMIC AND CONTROL GROUPS

\begin{tabular}{|c|c|c|c|c|c|c|c|c|c|c|}
\hline & & & \multirow[b]{2}{*}{1} & \multirow[b]{2}{*}{2} & \multicolumn{4}{|c|}{ Day of life } & \multirow[b]{2}{*}{7} & \multirow[b]{2}{*}{8} \\
\hline & Case & & & & 3 & 4 & 5 & 6 & & \\
\hline 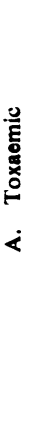 & $\begin{array}{l}1 \\
2 \\
3 \\
4 \\
5 \\
6 \\
7 \\
8 \\
9 \\
10 \\
11 \\
11 \\
12 \\
13 \\
14 \\
15 \\
16 \\
17 \\
18 \\
19 \\
20\end{array}$ & $\begin{array}{l}\ldots \\
\therefore \\
\therefore \\
\therefore \\
\therefore \\
\therefore \\
\therefore \\
\therefore \\
\therefore \\
\therefore \\
\therefore \\
\therefore \\
\therefore \\
\therefore \\
\therefore \\
\therefore\end{array}$ & $\begin{array}{l}50 \\
55 \\
40 \\
45 \\
50 \\
35 \\
35 \\
65 \\
40 \\
45 \\
45 \\
45 \\
50 \\
55 \\
45 \\
40 \\
60 \\
60 \\
65 \\
65\end{array}$ & $\begin{array}{l}50 \\
60 \\
60 \\
65 \\
45 \\
50 \\
40 \\
85 \\
45 \\
65 \\
45 \\
55 \\
45 \\
45 \\
60 \\
60 \\
45 \\
55 \\
70 \\
65\end{array}$ & $\begin{array}{l}45 \\
55 \\
65 \\
70 \\
65 \\
60 \\
50 \\
70 \\
70 \\
65 \\
50 \\
65 \\
60 \\
50 \\
65 \\
60 \\
90 \\
75 \\
65 \\
75\end{array}$ & $\begin{array}{l}85 \\
65 \\
60 \\
75 \\
85 \\
60 \\
45 \\
80 \\
50 \\
65 \\
65 \\
80 \\
65 \\
65 \\
70 \\
80 \\
60 \\
90 \\
75 \\
85\end{array}$ & $\begin{array}{l}65 \\
60 \\
65 \\
60 \\
85 \\
50 \\
70 \\
75 \\
75 \\
65 \\
70 \\
60 \\
60 \\
60 \\
80 \\
80 \\
95 \\
70 \\
60 \\
70\end{array}$ & $\begin{array}{l}75 \\
60 \\
60 \\
70 \\
85 \\
65 \\
65 \\
75 \\
65 \\
65 \\
65 \\
60 \\
75 \\
85 \\
75 \\
80 \\
75 \\
70 \\
65 \\
95\end{array}$ & $\begin{array}{l}75 \\
85 \\
70 \\
85 \\
85 \\
65 \\
40 \\
60 \\
80 \\
75 \\
75 \\
85 \\
70 \\
95 \\
65 \\
85 \\
75 \\
75 \\
70 \\
70\end{array}$ & $\begin{array}{r}70 \\
70 \\
65 \\
85 \\
100 \\
70 \\
55 \\
85 \\
80 \\
75 \\
80 \\
85 \\
70 \\
70 \\
75 \\
75 \\
85 \\
80 \\
70 \\
90\end{array}$ \\
\hline 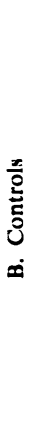 & $\begin{array}{r}1 \\
2 \\
3 \\
4 \\
5 \\
6 \\
7 \\
8 \\
9 \\
10 \\
11 \\
12 \\
13 \\
14 \\
15 \\
16 \\
17 \\
18 \\
19 \\
20\end{array}$ & $\begin{array}{l}\ldots \\
\cdots \\
\cdots \\
\cdots \\
\cdots \\
\cdots \\
\cdots \\
\cdots \\
\cdots \\
\cdots \\
\cdots \\
\cdots \\
\therefore \\
\cdots \\
\cdots\end{array}$ & $\begin{array}{l}55 \\
30 \\
45 \\
45 \\
45 \\
40 \\
45 \\
55 \\
45 \\
40 \\
55 \\
45 \\
55 \\
60 \\
45 \\
45 \\
65 \\
50 \\
40 \\
50\end{array}$ & $\begin{array}{l}50 \\
60 \\
65 \\
70 \\
70 \\
65 \\
55 \\
65 \\
45 \\
45 \\
45 \\
65 \\
65 \\
65 \\
65 \\
95 \\
65 \\
50 \\
60 \\
50\end{array}$ & $\begin{array}{l}45 \\
55 \\
65 \\
70 \\
65 \\
65 \\
65 \\
60 \\
45 \\
55 \\
45 \\
65 \\
50 \\
65 \\
65 \\
60 \\
65 \\
60 \\
55 \\
50\end{array}$ & $\begin{array}{l}65 \\
50 \\
65 \\
70 \\
75 \\
65 \\
65 \\
75 \\
65 \\
75 \\
55 \\
60 \\
75 \\
80 \\
65 \\
75 \\
70 \\
70 \\
55 \\
55\end{array}$ & $\begin{array}{l}65 \\
55 \\
75 \\
45 \\
75 \\
80 \\
70 \\
85 \\
85 \\
55 \\
65 \\
65 \\
65 \\
75 \\
75 \\
65 \\
75 \\
80 \\
65 \\
95\end{array}$ & $\begin{array}{l}65 \\
65 \\
65 \\
65 \\
75 \\
75 \\
80 \\
85 \\
85 \\
60 \\
75 \\
65 \\
85 \\
95 \\
80 \\
60 \\
65 \\
75 \\
65 \\
80\end{array}$ & $\begin{array}{r}70 \\
55 \\
80 \\
60 \\
70 \\
100 \\
85 \\
85 \\
105 \\
55 \\
75 \\
70 \\
75 \\
90 \\
85 \\
85 \\
70 \\
75 \\
70 \\
85\end{array}$ & $\begin{array}{l}75 \\
65 \\
70 \\
60 \\
85 \\
95 \\
75 \\
85 \\
85 \\
65 \\
85 \\
65 \\
85 \\
80 \\
75 \\
75 \\
80 \\
80 \\
75 \\
85\end{array}$ \\
\hline
\end{tabular}

Twelve infants in the control group, in whom readings were taken on the first and eighth day only, had a lower pressure on the eighth day than on the first.

The above findings indicate that the systolic blood pressure is similar during the first eight days of life in the infants of toxaemic mothers and in controls. In both groups there is a tendency for the blood pressure to rise during the first eight days, and although the rise is not necessarily steady or consistent, the distribution of readings at the beginning and end of the period is similar in both groups. Fallacies in the technique of recording pressures would affect both groups equally, and the results are therefore comparable.

\section{Premature Births}

The incidence of stillbirth and neonatal death in toxaemic and in non-toxaemic pregnancy terminating prematurely was calculated on the basis of all the premature births occurring in the hospital over a three-year period. For some of the figures on which these calculations are based I am indebted to Dr. C. M. Drillien.

\section{Toxaemic Control}

Stillbirth 19 per cent. 23.9 per cent.

Neonatal death $20 \cdot 8$ per cent. $27 \cdot 2$ per cent.

The progress of the surviving premature infants has been compared by estimating the rate of gain in weight of all such infants over $2 \frac{1}{2} \mathrm{lb}$. treated during one year, whether born in the hospital or admitted from the hospital district on account of prematurity within a few hours of birth. The infants were divided into sub-groups on the basis of birthweight, and the average weight of the subgroup at weekly intervals was calculated; toxaemic and control groups were then compared in each instance.

It was found that in four of the nine sub-groups the progress of the 'toxaemic' prematures was slightly superior to that of the controls, in two it was slightly inferior, and in three instances the curves showed no significant difference. It is concluded that the progress of prematurely born infants, over periods of four to twelve weeks in hospital, was at least as good in the case of the infants of toxaemic mothers as in the case of infants where prematurity was due to some other cause. (The detailed figures are given elsewhere, Brash, 1948.)

Incidence of prematurity. Fig. 4 shows the distribution of birthweights in two thousand consecutive live births, divided into toxaemic and

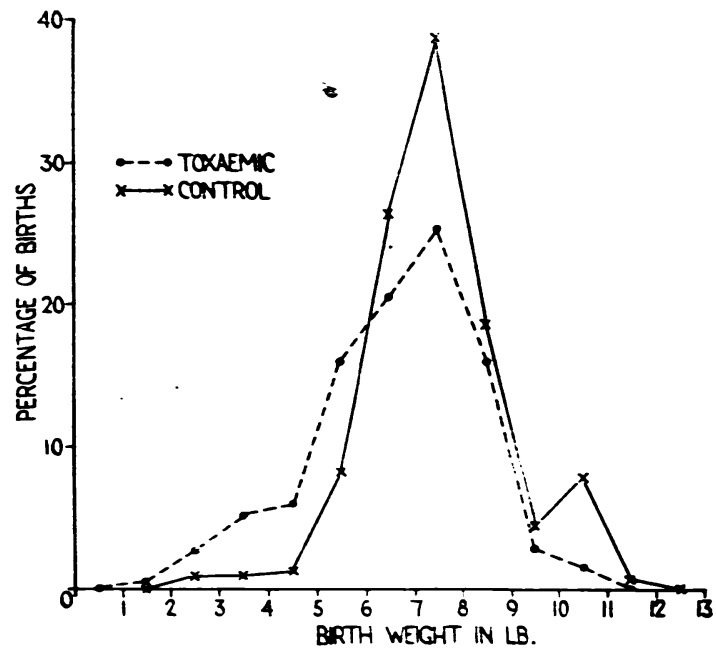

Fig. 4.-Percentage distribution of birthweights in two thousand consecutive live births. 
non-toxaemic groups, the number in each weightrange being expressed as a percentage of the total births to toxaemic and non-toxaemic mothers respectively. The incidence of prematurity is seen to be significantly greater in the toxaemic than in the non-toxaemic group.

\section{Stillbirths}

The incidence of stillbirth in toxaemic and in non-toxaemic pregnancy was calculated on the basis of all the births occurring in the hospital over a three-year period. The incidence of stillbirth in 756 pregnancies complicated by toxaemia was 10.7 per cent.; that in 8,313 pregnancies not so complicated was 3.9 per cent.

In each of the two hundred cases in this series (one hundred toxaemic, one hundred non-toxaemic) a study was made of the antenatal history, the labour, and the delivery, together with a postmortem report on the infant where available. The maternal history was considered in each case, and the cases showing abnormal factors which might cause foetal death were grouped together. The results are shown in table 3.

TABLE 3

ANTENATAL HISTORY, LABOUR, AND DELIVERY

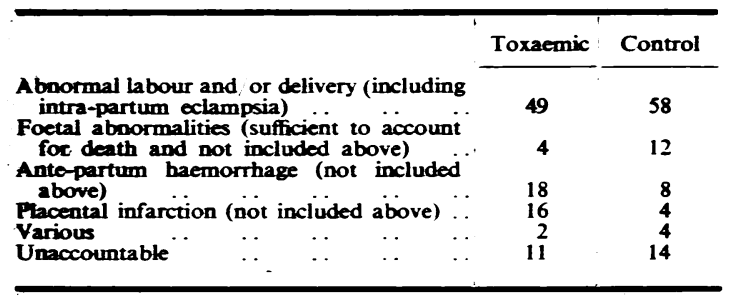

Necropsies were performed on thirty-eight infants in the toxaemic group and thirty-five in the control. Table 4 shows the causes of death reported in these cases.

TABLE 4

CAUUSES OF DEATH

\begin{tabular}{lcccccc}
\hline & & & \multicolumn{2}{c}{ Toxaemic } & Control \\
\cline { 3 - 5 } & & & & & 23 & 18 \\
Asphyxia & $\ldots$ & $\ldots$ & $\ldots$ & $\ldots$ & 8 & 8 \\
Not determined & $\ldots$ & $\ldots$ & $\ldots$ & $\ldots$ & 7 & 9 \\
\hline
\end{tabular}

In no case in either group were toxic changes found in the liver or kidneys.

\section{Neonatal Deaths}

The incidence of neonatal death in toxaemic and in non-toxaemic pregnancy was calculated on the basis of all the births occurring in the hospital over a three-year period. The incidence of neonatal death in 756 pregnancies complicated by toxaemia was $5 \cdot 2$ per cent.; that in 8,313 pregnancies not so complicated was 2.9 per cent. (There is a possible source of error in this calculation, in that deaths occurring after discharge from hospital but within the neonatal period are not included; the number of these is certainly very small.)
In each of the two hundred cases in this series a study was made of the antenatal history, the labour, and the delivery, the clinical record of the infant, and the post-mortem report where available.

Fig. 5 shows the age at death by means of a cumulative curve showing the number dead on each

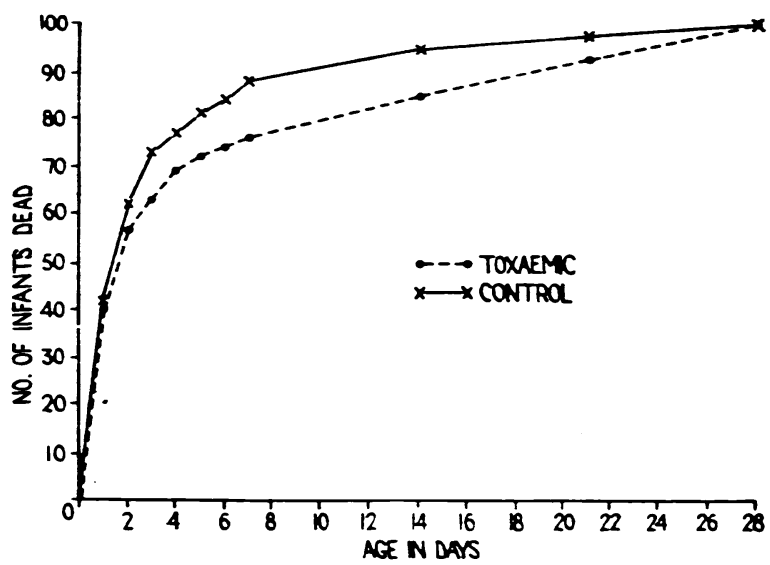

Fig. 5.-Cumulative curve to show age at death.

day of the first week, and at the end of each subsequent week of the neonatal period. It will be seen that the vast majority of the deaths occurred within the first few days of life, and that the curves are similar for the toxaemic and control groups.

In analysing the causes of the deaths, those occurring within the first five days were considered as one group, and those occurring later as another, because the majority of deaths in the first four or five days may justly be attributed to obstetric factors, while those occurring after the fourth or fifth day are commonly due to factors arising after birth.

The infants were further subdivided into groups according to birthweight, the term 'pre-viable' being applied arbitrarily to those weighing less than $2 \frac{3}{4} \mathrm{lb}$. (1,250 g.) and 'premature' to those weighing from $2 \frac{3}{4} \mathrm{lb}$. to $5 \frac{1}{2} \mathrm{lb}$. (1,250 g. to $2,500 \mathrm{~g}$.).

Necropsies were performed on eighty-nine infants in the toxaemic and ninety-two in the control group. The findings are summarized in tables 5 and 6 , the term asphyxia being used to include post-asphyxial pneumonia.

TABUE 5

DEATHS WITHIN THE FIRST FIVE DAYS

\begin{tabular}{|c|c|c|c|c|c|c|c|c|}
\hline & \multicolumn{2}{|c|}{ Pre-viable } & \multicolumn{2}{|c|}{ Premature } & \multicolumn{2}{|c|}{ Mature } & \multicolumn{2}{|c|}{ Total } \\
\hline & $\begin{array}{l}\text { Tox- } \\
\text { aemic }\end{array}$ & $\begin{array}{l}\text { Con- } \\
\text { trol }\end{array}$ & $\begin{array}{c}\text { Tox- } \\
\text { aemic }\end{array}$ & $\begin{array}{l}\text { Con- } \\
\text { trol }\end{array}$ & $\begin{array}{c}\text { Tox- } \\
\text { aemic }\end{array}$ & $\begin{array}{c}\text { Con- } \\
\text { trol }\end{array}$ & $\overline{\text { Tox- }}$ & $\begin{array}{c}\text { Con- } \\
\text { trol }\end{array}$ \\
\hline Asphyxia. & 13 & 27 & 23 & 30 & 7 & 8 & 43 & 65 \\
\hline $\begin{array}{c}\text { thage } \\
\text { Other causes }\end{array}$ & $\begin{array}{l}3 \\
6\end{array}$ & $\begin{array}{l}1 \\
3\end{array}$ & $\begin{array}{l}6 \\
5\end{array}$ & $\overline{3}$ & $\begin{array}{l}2 \\
2\end{array}$ & $\begin{array}{l}1 \\
6\end{array}$ & $\begin{array}{l}11 \\
13\end{array}$ & $\begin{array}{r}2 \\
12\end{array}$ \\
\hline mined & - & - & 2 & 1 & 1 & 1 & 3 & 2 \\
\hline Total & 22 & 31 & 36 & 34 & 12 & 16 & 70 & 81 \\
\hline
\end{tabular}


TAME 6

DEATHS AFTER THE FIFTH DAY

\begin{tabular}{|c|c|c|c|c|c|c|c|c|}
\hline & \multicolumn{2}{|c|}{ Pro-viable } & \multicolumn{2}{|c|}{ Premature } & \multicolumn{2}{|c|}{ Mature } & \multicolumn{2}{|c|}{ Total } \\
\hline & Tox- & Coo- & Tox- & $\underset{\text { trol }}{\text { Con- }}$ & $\begin{array}{l}\text { Tox- } \\
\text { aemic }\end{array}$ & $\underset{\text { trol }}{\text { Con- }}$ & $\begin{array}{l}\text { Tox- } \\
\text { acmic }\end{array}$ & $\underset{\text { trol }}{\text { Con- }}$ \\
\hline \multirow{3}{*}{$\begin{array}{l}\text { Pneumonia } \\
\text { Gastro- } \\
\text { enteritis } \\
\text { Other causes } \\
\text { Cause not } \\
\text { deter- } \\
\text { mined }\end{array}$} & 3 & - & 10 & 9 & 2 & 3 & 15 & 12 \\
\hline & - & $\overline{2}$ & $\begin{array}{l}7 \\
2\end{array}$ & 1 & 2 & 3 & $\begin{array}{l}9 \\
4\end{array}$ & $\begin{array}{l}1 \\
5\end{array}$ \\
\hline & - & - & 2 & - & - & 1 & 2 & 1 \\
\hline Total & 3 & 2 & 21 & 10 & 6 & 7 & 30 & 19 \\
\hline
\end{tabular}

In the group dying within five days there appears to be a relative preponderance of intracranial haemorrhage in the premature infants of toxaemic mothers. The criterion adopted for assessing intracranial haemorrhage as the cause of death was severe haemorrhage with no more than slight evidence of asphyxia. It is nevertheless impossible to be certain that even severe haemorrhage was not due to asphyxia, and that most of these cases should not therefore be included under the latter heading.

Asphyxia without a recognizable cause, such as abnormality of labour or delivery, ante-partum haemorrhage, or placental infarction, was found in nine cases in the toxaemic and twenty-one in the

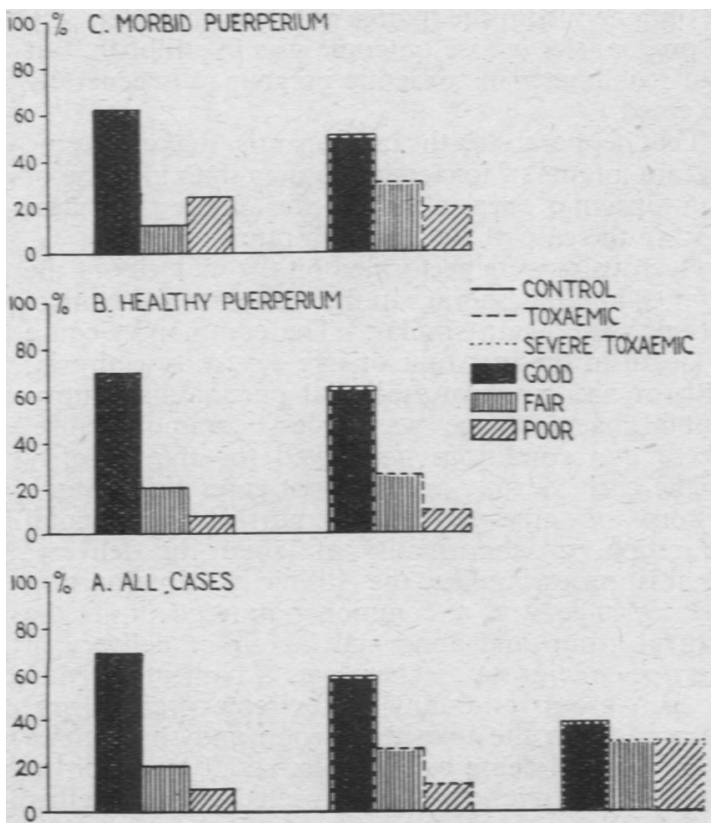

Fig. 6.-Relationship of lactation (good, fair, or poor) to toxaemia and type of puerperium (healthy or morbid). control group, of which eight in the toxaemic and eleven in the control group were below $2 \frac{3}{4} \mathrm{lb}$. at birth.

The cause of death remained undetermined in five cases in the toxaemic group and three in the control. Of those in the toxaemic group, one was a mature infant who had been delivered abnormally and who died before the fifth day; the other four were premature infants whose deaths could not be accounted for clinically, and necropsies carried out on two were inconclusive. Of those in the control group, one was a premature infant dying within the first two days, whose mother had ante-partum haemorrhage and whose placenta was infarcted; one was a mature infant dying within the first few days who had been -delivered abnormally and who showed clinical signs of intracranial haemorrhage; the third was a mature infant dying after the fifth day on whom necropsy was inconclusive.

In this series toxic or degenerative changes in the liver and kidneys were found at necropsy as follows:

Toxaemic. Two infants showed toxic changes in both liver and kidneys; both were more than five days old and died of staphylococcal pneumonia. Two showed hydropic degeneration of the liver; both were under five days old: one was asphyxiated, and the other had severe intracranial haemorrhage and also pulmonary and renal haemorrhage.

Control. One infant showed toxic changes in both liver and kidneys; this infant was under five days old and was thought, but not proved, to have streptococcal septicaemia. Ten showed fatty degeneration of the liver; eight of these were under five days and were asphyxiated; two were over five days and had pneumonia. One showed toxic changes in the kidneys only; this child was under five days and was asphyxiated.

\section{Lactation}

The adequacy of maternal lactation was assessed in the series of one hundred and twenty full-term infants of toxaemic mothers and the corresponding series of one hundred and twenty non-toxaemic controls. As daily test-weighing of all infants at all feeds was impracticable, the assessment (which is admittedly only a rough index of lactation) was based on satisfactory gain in weight of the infant in the first instance. Where the gain in weight was not fully satisfactory, test-feeds showing an average of $2 \mathrm{oz}$. or more per feed at the end of the first week were regarded as evidence of good lactation. Lactation was graded as poor if test-feeds were consistently under $1 \frac{1}{2} \mathrm{oz}$. Intermediate cases were classified as fair.

The lactation of toxaemic and non-toxaemic women was compared on this basis, and the groups again compared after dividing into those with a healthy and those with a morbid puerperium. The results are shown in table 7. 
TABuE 7

LACTATION OF TOXAEMIC WOMEN AND CONTROLS, EXPRESSED PER CENT.

\begin{tabular}{|c|c|c|c|c|c|c|}
\hline \multirow[b]{2}{*}{ Lactation } & \multicolumn{2}{|c|}{ All cases } & \multicolumn{2}{|c|}{$\begin{array}{l}\text { Healthy } \\
\text { puexperium }\end{array}$} & \multicolumn{2}{|c|}{$\begin{array}{c}\text { Morbid } \\
\text { puerperium }\end{array}$} \\
\hline & $\begin{array}{l}\text { Tox- } \\
\text { aemic }\end{array}$ & $\underset{\text { trol }}{\text { Con- }}$ & $\begin{array}{l}\text { Tox- } \\
\text { acmic }\end{array}$ & Con- & $\begin{array}{l}\text { Tox- } \\
\text { acmic }\end{array}$ & $\begin{array}{l}\text { Con- } \\
\text { trol }\end{array}$ \\
\hline $\begin{array}{l}\text { Good } \\
\text { Fair } \\
\text { Poor }\end{array}$ & $\begin{array}{l}59 \\
27 \\
14\end{array}$ & $\begin{array}{l}70 \\
20 \\
10\end{array}$ & $\begin{array}{l}63 \\
26 \\
11\end{array}$ & $\begin{array}{r}70 \\
21 \\
9\end{array}$ & $\begin{array}{l}50 \\
31 \\
19\end{array}$ & $\begin{array}{l}62 \cdot 5 \\
12 \cdot 5 \\
25\end{array}$ \\
\hline
\end{tabular}

In fig. 6 the relationship of lactation to toxaemia is shown graphically, and the cases of severe toxaemia are also shown separately. It is clear that the toxaemic women lactated less well than the controls, and that those with severe toxaemia lactated less well than those where toxaemia was mild or moderate. Puerperal morbidity, as would be expected, is shown to have an adverse effect on lactation in both toxaemic women and controls.

Whilst the finding that lactation was less good in toxaemic women than in controls confirms Peckham's (1933) opinion, it is possibly related to the fact that the number of abnormal labours and deliveries, with the consequent administration of sedatives and anaesthetics, was higher in the toxaemic than in the control group. Ludlow (1933) found that there were no ill effects attributable to the breast milk of toxaemic mothers, and the present investigation confirms this view.

\section{Discussion}

The stillbirth rate for mature infants is considerably higher in the presence of the toxaemia of pregnancy than its absence, and the question arises whether this is due directly to a lethal effect of the maternal condition upon the foetus; that is, to some substance circulating in the maternal blood and passing the placental barrier to reach the foetal circulation, or to an increased incidence of the same factors which cause stillbirth in the absence of toxaemia.

In this series the findings in the limited number of necropsies carried out were similar in the toxaemic and in the control groups, asphyxia being the cause of death in the majority and intra-cranial haemorrhage in a smaller number. In a fair proportion the cause of death could not be determined at necropsy, but as the number was greater in the control than in the toxaemic group a hypothetical toxin cannot be held responsible. In no case were toxic changes, such as have been described by Esch and other authors, found to be present. The number submitted to necropsy in this particular series was small, but Dr. A. R. Macgregor in a very large number of necropsies has never seen such changes (personal communication). Autolysis, placental infarction, asphyxia, and maceration, all found frequently in the offspring of non-toxaemic mothers, do not merit the description 'evidence of toxaemia given them by Ludlow.
The cases examined post mortem being a minority, an attempt was made to assess the cause of stillbirth from the obstetric history. Conditions which may lead to foetal asphyxia are ante-partum haemorrhage, placental infarction, and abnormality in the course of labour or delivery, the last being sometimes associated also with intracranial haemorrhage. The majority of cases in both groups had a history of one or more of these conditions, ante-partum haemorrhage and placental infarction being more frequent antecedents in the toxaemic group, and abnormal labour or delivery in the control group.

A substantial minority in the control group and a few in the toxaemic were due to gross developmental abnormality of the foetus.

An appreciable number remain in which no ante- or intra-partum factor can be held accountable for the stillbirth, and these include a few cases in which evidence of asphyxia was found at necropsy, but here again the greater number in the control than in the toxaemic group precludes the drawing of any deductions about possible toxins.

The conclusion to be drawn is that while stillbirth is commoner in toxaemic than in non-toxaemic pregnancy, its pathological causes in the two groups are essentially the same, the principal one being asphyxia. It thus appears that the presence of toxaemia renders the foetus more liable to be asphyxiated, presumably as a result of the higher incidence of ante-partum haemorrhage and placental infarction in toxaemic than in normal pregnancy. (The incidence of these conditions cannot, of course, be obtained from the figures given, which refer only to pregnancies whose outcome was in stillbirth, but that it is higher in toxaemic pregnancy is generally accepted.)

The neonatal death rate also is higher in the mature infants of toxaemic mothers than in those of non-toxaemic ones, although the difference is less than in the case of the stillbirth rate.

Necropsies were performed on the majority of the infants, and the findings in the toxaemic and control groups were again similar. The commonest cause of death in the first four or five days was asphyxia, with or without post-asphyxial pneumonia; intracranial haemorrhage was a less common cause. These two conditions accounted for the majority of the early deaths, and in most cases there was a history of ante-partum haemorrhage, placental infarction, or abnormality. of labour or delivery. In this series, unlike the stillbirths, ante-partum haemorrhage was a commoner antecedent in the control group and abnormal labour or delivery in the toxaemic group. There was a high proportion in each group of infants of extreme prematurity; twenty-five in the toxaemic group and thirty-three in the control being below $2 \frac{3}{4} \mathrm{lb}$. $(1,250 \mathrm{~g}$.) at birth; these infants might well be expected to die whether asphyxiated or not.

Asphyxia without any recognizable ante- or intra-partum cause occurred in a number of cases, greater in the control than in the toxaemic group, 
and in most instances in extremely premature infants.

Deaths occurring after the fifth day were nearly all due to infection, the majority to pneumonia and a number to gastro-enteritis.

The cause of death remained undetermined in a few cases in each group. In this series toxic or degenerative changes were found in the liver and/or kidneys in four infants in the toxaemic and twelve in the control group; all were associated either with asphyxia or with infection, and none could be described as ' eclamptic changes'.

The causes of neonatal death, like those of stillbirth, are thus the same in the infants of toxaemic and of non-toxaemic mothers. The findings in this investigation support the opinion of Esch (quoted by Tunis) on the importance of prematurity and of difficulties in labour or delivery, and those of Tunis (1928) and Strauch (1939) on the additional role of disturbance of the placental circulation by placental infarction or ante-partum haemorrhage. Tyson and Bowman (1931) ascribed the high mortality among the infants of toxaemic mothers solely to premature birth, but this would seem to be unjustified. The point is of importance, for if prematurity were the sole cause of death in these infants then the interest of the infant would demand that pregnancy be allowed to continue as long as possible, whereas if it is increasingly subject to the risk of intra-uterine asphyxia its interest would coincide with that of the mother, which often calls for the termination of pregnancy before term, a living infant, although handicapped by prematurity, being preferable to a mature one which is stillborn or dies shortly after birth.

Drillien (1947a), who emphasizes the role of toxaemia in the etiology of premature birth and hence in that of neonatal death, suggests also that it may play an important part in causing intrauterine deaths.

It is noteworthy that whereas in the control group all save one of the seventy-seven premature births were the result of spontaneous onset of labour, in the toxaemic group thirty-two out of sixty-one premature infants were born as the result of an induction of labour.

When the stillbirth and neonatal death rates for premature infants are separated from the general figures the odd fact emerges that the premature infants of toxaemic mothers actually fared better than those of non-toxaemic ones. This is in agreement with Ludlow's findings (1933), and also with those of Drillien (1947a); the reason for it is obscure. The surviving infants find their mothers' toxaemia no handicap, as they make at least as good progress as the infants of healthy women.

The greater part of this investigation has been concerned with mature living infants. If a toxic substance, whether of a hypertensive or other nature, is formed in the maternal organism, or more particularly in the placenta, and circulates in the maternal blood stream to produce the signs and symptoms of the toxaemia of pregnancy, it might be expected to enter the foetal circulation and produce its effects there also; were such a substance formed by the foetus it is hardly conceivable that it could produce such extensive effects upon the mother and none upon the foetus itself.

Ways in which maternal toxaemia might be thought capable of affecting the infant are, in addition to the particular features of oedema, albuminuria, and hypertension, impairment of general progress with less than satisfactory gain in weight and possibly undue sleepiness and slowness, and greater liability to infections.

Progress, as judged by gain in weight, has been shown to be as good in the toxaemic as in the control group.

While there were more lethargic babies in the toxaemic group than in the control, this may possibly be accounted for by inductions of labour and sedatives given to the mother before delivery. The only other explanation for undue sleepiness which might be advanced would be cerebral oedema occurring as part of a generalized oedema. Manifest oedema is rare in full-term infants; occult oedema would show itself in a big loss of weight in the first few days of life, and it has been shown that the initial loss is not significantly greater, weight for weight, in the toxaemic than in the control group.

Albuminuria was found considerably less often, in the small number of specimens examined, in the toxaemic than in the control group; small as the numbers are, the findings certainly do not support Salmi's statement that albuminuria is commoner in the infants of albuminuric than in those of healthy mothers.

The estimations of the systolic blood pressure gave an average first day reading lower in the toxaemic group of seventy cases than in the control group of 120 cases, though this difference is not observed in the smaller groups on which daily readings were made. The observed variation of the pressure with birthweight and length (the average birthweight being lower in the toxaemic group than in the control) does not account for this difference on the first day. The average eighth day reading was almost identical in the two groups. The few infants of severely toxaemic mothers on whom readings were made gave averages lower than the remainder in the toxaemic group. The daily readings in each group show no consistent form of curve, though in the great majority of cases the reading was 20 to $30 \mathrm{~mm}$. higher on the eighth day than on the first.

The infants in the toxaemic group showed no greater liability to infection or any other morbid condition than the controls, and nothing resembling neonatal eclampsia, either clinically or pathologically, was encountered in the series of survivors or in the stillbirth or neonatal death series.

\section{Summary and Conclusions}

1. The incidence of stillbirth and the occurrence of neonatal death have been found to be higher in 
infants born at term to toxaemic women than in the full-term infants of non-toxaemic women delivered in the same hospital. The principal cause in both cases is the greater liability to asphyxia resulting from ante-partum haemorrhage and placental infarction. No post-mortem evidence has been found to support the view that toxic changes in the foetus occur as the direct result of maternal toxaemia.

2. Full-term infants (of toxaemic mothers) who survived showed no greater liability to infection, and no less satisfactory progress as judged by gain in weight during the neonatal period, than the infants of non-toxaemic controls.

3. A higher incidence of neonatal oedema was found in the full-term infants of toxaemic mothers than in controls.

4. In a small series of cases, albuminuria on the third day of life occurred less frequently in the infants of toxaemic mothers than in controls.

5. A comparison has been made of systolic blood-pressure readings in full-term infants of toxaemic and non-toxaemic women during the first eight days of life, and the findings discussed.

6. The incidence of premature labour was found to be significantly higher in toxaemic women than in non-toxaemic women delivered in the same hospital during the same period.

7. The stillbirth rate and neonatal mortality rate of premature infants born to toxaemic women were lower than those of premature infants born to non-toxaemic women in the same hospital.

8. The progress, judged by gain in weight, of premature infants born to toxaemic women compared favourably with that of groups of premature infants of similar birthweights born to non-toxaemic women.

9. Lactation of toxaemic women was less satisfactory than that of non-toxaemic controls.

10. Severe toxaemia was found to have a more adverse effect on lactation than mild toxaemia.

I wish to thank Prof. R. W. B. Ellis and Prof. R. J. Kellar for permission to quote from the records of the Simpson Memorial Maternity Pavilion, and Dr. A. R. Macgregor for permission to quote post-mortem reports; also Dr. B. A. Woolf for advice on the presentation of graphs and tables.

\section{REFERENCES}

Brash, A. A. (1948). M.D. Thesis, University of Edinburgh.

Browne, F. J., and Dodds, G. H. (1936). Lancet, 1, 1059.

Day, R. (1939). J. Pediat., $14,148$.

Drillien, C. M. (1947a). J. Obstet. Gynaec Brit. Emp., 54,300 . (1947b). Ibid., 54, 443. (1947c). Ibid., 54, 452.

Hallum, J. L. (1941). M.D. Thesis, University of St. Andrews.

Ludlow, G. C. (1933). Amer. J. Dis. Child., 45, 1223.

Peckham, C. H. (1933). J. Amer. med. Ass., 101, 1608.

Rucker, M. P., and Connell, J. W. (1924). Amer.J. Dis. Child., 27, 6.

Smith, C. A. (1945). The Physiology of the Newborn Infant. Springfield, Charles C. Thomas.

Strauch, H. (1939). Geburtsh. u. Freauenheilk., 1, 671.

Tunis, B. (1928). Z Zbl. Gynäk., 52, 1928.

Tyson, R. M., and Bowman, J.E. (1931). Arch. Pediat., 48, 270.

Woodbury, R. A., Robinow, M., and Hamilton, W. F. (1938). Amer. J. Physiol., 122, 472.

Young, W. F., Hallum, J. L., and McCance, R. A. (1941). Arch. Dis. Childh., 16, 243. 